\title{
Attitudes Toward the LGBT: A Research Paper Presented to the Faculty of the Senior High School Department Iligan City National High School
}

Shaynie T Duhaylungsod, Cheska Grace Y Madrid, Mae Leamor M Lapiz, Cristine S Pongasi*, Lea May P Tan

Iligan City National High School, St., Mahayahay, Iligan City, Philippines

\begin{abstract}
Stereotyping, gender discrimination, and oppression are still exists in this society. In order to know the recent views or perspective of people towards lesbian, gay, bisexual, transgender (LGBT) a study conducted. The study investigated attitudes toward LGBT by surveying 86 students from Iligan City National High School and 14 teachers from senior high school department. It was hypothesized that there will be more negative reactions than positive attitudes. A results have shown that majority of the respondents have accept and support the LGBT people and are able to become one of the ally. The findings from this study can be used to acquire knowledge to people about societal attitudes to decrease any oppression or gender discrimination.
\end{abstract}

Keywords: Discrimination; Stereotyping; Homosexuality; LGBT; Students and teachers attitudes

\section{The Problem and Its Scope}

"Race, gender, religion, sexuality, we are all people and that's it. We're all people. We're all equal.” That is according to Conor Franta. Whatever your gender, race, religion, and sexuality is, you're still the person which you are now. Your sexual preference doesn't define you, it is your personality that aspire you to be who you are in the society where you belong. But there are still people who do not yet accept the third sex in the community.

Attitude is determined as "a predisposition or a tendency to respond positively or negatively to a certain idea, object, person, or situation" [1]. A person have two angles in viewing a certain person or peers that is involve in a society, its either positive or negative. On the other hand, an attitude is "a relatively enduring organization of beliefs, feelings, and behavioral tendencies towards socially significant objects, groups, events or symbols". We all know that we live in a society with a group of different people that has different perceptions. Like, the negative stereotypical thoughts arise from proximity and social knowledge of out groups; and in the case of heterosexual-homosexual dynamics, they may also serve as a safety mechanism used to enforce group superiority and normalcy. That means that society still exhibit ambivalence of the inclusive acceptance of homosexuality today.

The widespread of LGBT community has awakening the social perspectives of the society towards them. This study could not only benefits to the researchers but also for the whole community. It may change their views, perceptions, and beliefs in the LGBT community. Nowadays the researchers have seen a lot of changes towards the LGBT community. On how they interact, and build their self in the society just for them to be accepted.

The purpose of the study is to know what heterosexual people sees homosexual as their friends and how do they interact with them and also to acknowledge the society about how homosexuality approach the heterosexuality in the $21^{\text {st }}$ century. This present study was intended to achieve the views and perceptions of heterosexuality towards the lesbian, gay, bisexual, and transgender in the society. The study beset 3 main objectives: To explore current views and perceptions of heterosexuality towards homosexuality. To discover how people deal and how they interact with homosexuality. To examine their basis on how they come up with such an attitude towards homosexuality.

\section{Theoretical framework}

In the present study, the researchers used the functionalist theory of Daniel Katz. Daniel Katz proposed the theory of attitudes. He takes the view that attitudes are determined by the functions they serve for us. People hold given attitudes because these attitudes help them achieve their basic goals. There are 3 components of attitudes according to Daniel Katz. Cognitive - our thoughts, beliefs, and ideas about something. When a human being is the object of an attitude, the cognitive component is frequently a stereotype, e.g. "welfare recipients are lazy". Affective - feelings or emotions that something evokes. e.g. fear, sympathy, hate. May dislike welfare recipients. Conative, or behavioral - tendency or disposition to act in certain ways toward something. Might want to keep welfare recipients out of our neighborhood. Emphasis is on the tendency to act, not the actual acting; what we intend and what we do may be quite different.

A favorable or unfavorable evaluative reaction toward something or someone, exhibited in ones beliefs, feelings, or intended behavior. It is a social orientation - an underlying inclination to respond to something either favorably or unfavorably. Katz distinguishes four types of psychological functions that attitudes meet. Instrumental - we develop favorable attitudes towards things that aid or reward us. We want to maximize rewards and minimize penalties. If an individual was being perceptive like, he/she have observe that most of the people in the society don't like folks in the LGBT community, then, he/she are more favor to go against the LGBT community. Knowledge attitudes provide meaningful, structured environment. In life we seek some degree of order, clarity, and stability in our personal frame of reference. Attitudes help supply us with standards of evaluation. Via such attitudes as stereotypes, we can bring order and clarity to the

*Corresponding author: Cristine S Pongasi, Iligan City National High School, St., Mahayahay, Iligan City, Philippines, Tel: +63-221 3814; E-mail: coolme2817@gmail.com

Received April 04, 2018; Accepted April 11, 2018; Published April 18, 2018

Citation: Duhaylungsod ST, Madrid CGY, Lapiz MLM, Pongasi CS, Tan LMP (2018) Attitudes Toward the LGBT: A Research Paper Presented to the Faculty of the Senior High School Department Iligan City National High School. Arts Social Sci J 9: 356. doi: 10.4172/2151-6200.1000356

Copyright: () 2018 Duhaylungsod ST, et al. This is an open-access article distributed under the terms of the Creative Commons Attribution License, which permits unrestricted use, distribution, and reproduction in any medium, provided the original author and source are credited. 
complexities of human life. Such as gender stereotypes in the society. Value-expressive - Express basic values, reinforce self-image. If you view yourself as a homophobic, you can reinforce that image by going against the LGBT community. Ego-defensive - Some attitudes serve to protect us from acknowledging basic truths about ourselves or the harsh realities of life. They serve as defense mechanisms. Katz says we develop attitudes that help us meet this goal.

Because gay people inevitably differ in characteristics irrelevant to their category membership. Heterosexuals with multiple contact experiences have increased opportunities for observing such variation and consequently, individuating outgrow members. Such individuation is likely to reduce intergroup prejudice. Close relationship with gay men or lesbians can provide heterosexuals with intimate, personally relevant information about gay people. They are likely to foster personalization of gay people, which helps to reduce prejudice. Discussions with a friend or relative about the latter's homosexuality can help to motivate the heterosexual person both to maintain the relationship and to change his/her attitudes towards gay people generally. Through this theory, the researchers can elaborate more about the attitudes of heterosexuality towards homosexuality. The 3 components will be considered as a guide for the researchers to determine the attitudes of the respondents.

\section{Statement of the problem}

Main problem: How do people approach and interact people in the third sex community?

Sub-problems: This study will determine the attitudes of SHS students and teachers toward the LGBT community. Specifically, this study will seek answer to the following question:

1. Respondent's profile.

2. What are the attitudes of SHS students and teachers towards the LGBT in terms of:

- Repulsion

- $\quad$ Pity

- Tolerance

- Acceptance

- $\quad$ Support

- Admiration

- Appreciation

- $\quad$ Nurturance

3. How do the attitudes shape their perceptions towards LGBT?

Conceptual framework: This study focuses on determining the attitudes of an individual towards the LGBT people by espousing the idea that attitudes may differ on how they view, treat, and communicate with people within the LGBT community. The researchers based their assumption from the Functionalist theory of Daniel Katz that attitudes are determined by the functions in which an individual may have. Also people have attitudes to meet their basic goals in life. In that case people could analyze their own attitudes based on how they interact, view, and treat the homosexuality.

For example, heterosexuality believe that there should be no homosexuality in the society. They are fear for what might the homosexuality bring in the society. Prejudices of heterosexuality towards the homosexuality that can result to hate or somehow it could be change if there is a motivational structure follows. These relationships will be more elaborated in Figure 1.

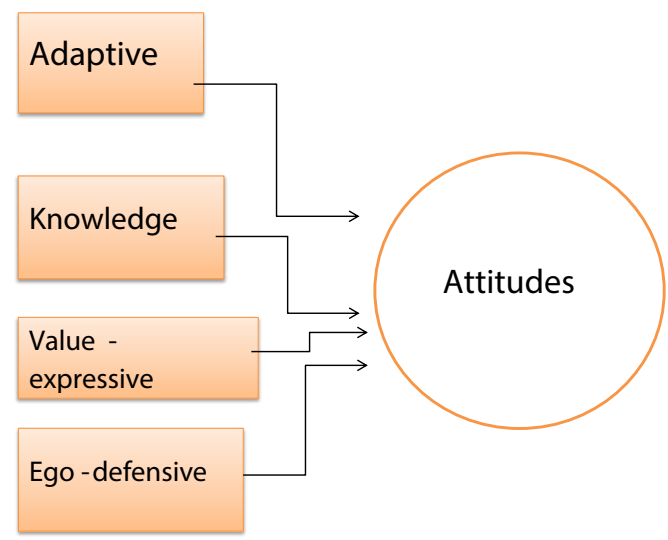

Figure 1: Mapping the relationship among the variables in this study

There are two components of variables: The independent variable which is known as manifest variables and can be measured readily. The four functions of attitudes according to the theory of Daniel Katz are manifest variables. The arrow shows a relationship between the four functions that will approximately result to the attitudes of the respondents. The dependent variable which is also known as latent variables that is cannot be measured readily. The attitude is one of the latent variables. In accordance of the functions, the effect of the latent variables show the corresponding attitudes. Positive and negative are considered as latent variables which incline to the positivity and negativity of an attitude that a person can have. Both variables are relation to each other. Lastly, the attitudes of heterosexuality has define.

Significance of the Study: People in the $21^{\text {st }}$ century has already aware of the LGBT community and through this, the researchers would like to know the recent attitudes of heterosexuality towards the LGBT. This will lead to acknowledge the people in the community according to the LGBT people and it will also help to change their views if in case they had been disgusted or angry towards their gender preference. This study will not only benefit the authors but eventually it will help to toil people in their perceptions and attitudes.

Scope and Limitation: Although the present study has several strengths, including collecting data from a large sample of Iligan City National High School, there are also limitations worth noting. This study aim to get the result at the due date of the research paper. First, the instrument used to assess attitudes was a one-dimensional questionnaire that could not make finer distinctions between attitudes toward male and female individuals who identify as bisexual, gay (men), or lesbian. As the literature points out, people sometimes differ in their attitudes toward these groups [2]. This present study is limited only to the chosen area which is the study to be conducted. It only focuses on perceiving the result of the views, interaction, and treatment of heterosexuality. There are no biases in this present study.

Definition of terms: The following terms defined the words used in the present study:

Attitude - A feeling or emotion toward a fact or state. (https://www. merriam-webster.com/dictionary/attitude).

Types of attitudes according Stephen P. Robbins and Mary Coulter:

- Positive attitude - The Persons, who will be possessing positive 
behavior, will explore good things in others and will not go after negativity.

- Negative attitude - Such type of persons are always prone to extreme degree of anger and carry the sentiments of hatred for others.

- Neutral attitude - Such type of persons remains self-satisfied and complacent. Their attitude is composed of indifference and detachment.

- Sikken attitude - This is most dangerous attitude because reflects the state of mind's negativity and possess enough potential to destroy the image of every related thing coming in mind.

Prejudice - an irrational attitude of hostility directed against an individual, a group, a race, or their supposed characteristics (https:// www.merriam-webster.com/dictionary/prejudice).

\section{Related Review of Related Literature and Studies}

Men and women have various attitudes towards LGBT community. Men's attitudes toward homosexuals are tend to be more negative than those of women. Attitudes towards the homosexual people, the sociodemographic correlates of these attitudes, and the potential gender differences, that means attitudes depends upon how people dealt with LGBT, has a distinctive correlation between the two. In some findings, women held more favorable attitudes than men and men held more favorable attitudes toward female than male homosexuality, whereas women did not differentiate [2]. If a heterosexual person with more interpersonal contact, their attitudes will be more favorable to the extent that they will evolve more close relationship and receiving direct disclosure about another's homosexuality. On the other hand, a study about homosexuality continue to say that homosexual relations should be neither acceptable nor legal. Prior knowledge to the study, these have been changes in attitudes as time goes by. Some people have already accept the third sex community but some are still on the personal discomfort with lesbians/gay men, institutional homophobia towards lesbian/gay men and the deviance/changeability factors were separate, they were highly correlated and showed little evidence of divergent validity. With the help of said theory, men and women did not differ in their overall level of homophobia. Both were associate with having a LGBT acquaintance and friends. Such an act may be occurring if a person is really against third sex community. This may result to stress for homosexual people. These stressors may include homophobic prejudice, social rejection, discrimination, and harassment [2]. Being confronted with these stressors, in turn, is linked with negative mental health outcomes, including depression, drug use, and suicide attempts. Since well-being among gay and lesbian people is a significant public health concern, in recent decades, many scholars in Western countries have addressed attitudes related to same-sex attraction and behavior, and policy makers have aimed to reduce discrimination and contribute to a generally positive social atmosphere [3]. Nonetheless, the attitudes of heterosexual may vary among the people within the society.

Other study focuses on the on the correlation of religion and views concerning homosexuality. Specifically, Christians will on average be more negative in their views towards homosexuality compared to Jews and those reporting no religious preference. Religious affiliations may affect an individual's attitude towards homosexuality like, when attitudes over a 20 or 30 year period are compared, fewer conservative Christians report believing homosexuality is morally wrong today than in the past though. While still the most condemning of homosexual behavior, evangelical Christians as a group are becoming more tolerant in their views toward homosexuality. Thus, religious people somehow did not accept homosexual in the community. The more literally people view the Bible the more intolerant they become towards certain fringe groups including homosexuals [4]. Also, as biblical literalism increases, believing homosexuality is always wrong increases as well [5]. In fact, religious individuals are selectively intolerant of homosexuals because they are perceived to be acting contrary to traditional religious teachings (Rowatt forthcoming).

Another one is attribution theory argues that causal attributions cause prejudice, and that changes in attribution beliefs produce changes in attitudes. Either internal or external attribution could lead to misinterpret or judging of homosexual in the society. Making an assumption towards them, is unethical.

\section{Review of related studies}

Many people tend to have a negative reaction when LGBT strikes, having the beliefs that being a lesbian/gay is wrong and sinful. Other feel uncomfortable and also confused on how they will interact with the LGBT. Through having this kind of attitude it may lead to discrimination and oppression of the LGBT people. But no matter who you are and what you have inside everyone must treat equally and must respect what they are. In 1998 people tried to discuss the side of negative attitude on how straight people interact with the LGBT. In the negative attitudes it is more likely on the tradition, on how they view LGBT, right wing people and the gender roles. Every people has its own view in LGBT so you cannot please them to respect and treat them equally. Acceptance is the only thing that LGBT wants in their life, but negative attitudes remain, because of the negative attitudes towards them they experience a minority stress. Having this stress may lead them to depression and suicide attempts. Gender-role beliefs are considered a very essential thing on the other hand the right-wing authoritarianism are those who really have the strong tradition and those people who are religious. But this study was all in the past, we may not know that study may change the people views and opinions about LGBT. In present time LGBT did strike people might think that they should treat equally and respectfully. This present study aim to modify the attitudes of the respondents with the support evidences of the related literature. However, the researchers might use the literature as the basis of the corresponding answers of the chosen respondents.

\section{Methodology \\ Research design}

This present study is aim to unleash the current attitudes from the sample group and to enable to use the data to broaden the view about a bigger population of similar students in the campus. This study is best described as cross-sectional study design because it was used to capture knowledge or attitudes one point at a time. The study used a nonprobability sampling because the researchers needed to gather data from the specific respondents. The questionnaire consisted mostly of closedended question whereas close-ended questions had options which were determined by the researcher. Students were approached who are willingly and potentially had the information that they could share and so purposive sampling was used. Finally the data was collected using self-administered questionnaires. Close-ended questions were included because they are easier to administer and to analyze. They are more efficient in the sense that a respondent is able to complete more close-ended items than open-ended items in a given period of time. This present study use a mixed methods and at the same time using correlational design. 
Citation: Duhaylungsod ST, Madrid CGY, Lapiz MLM, Pongasi CS, Tan LMP (2018) Attitudes Toward the LGBT: A Research Paper Presented to the Faculty of the Senior High School Department Iligan City National High School. Arts Social Sci J 9: 356. doi: 10.4172/2151-6200.1000356

Page 4 of 8

\section{Locale of the study}

The study was conducted in Ilgan City National High School, one of the public school in Iligan City, Lanao del Norte. Iligan City National High School teaches students in grades seventh to twelfth in Iligan City. It is specifically located at Gen Wood St. Mahayahay, Iligan City, 9200, Lanao Del Norte of Northern Mindanao (Region X), Philippines. The school consists of 111 instructional rooms and 9 non-instructional rooms. The school has 7, 121 students with the class size for each classroom ranges from 50-60 plus students. The population of teachers including the administrator is more or less than 300 (Figure 2).

\section{Respondents}

According to Burns and Grove, a population is defined as all elements (individuals, objects and events) that meet the sample criteria for inclusion in a study. Mouton defines a sample as elements selected with the intention of finding out something about the total population from which they are taken. A convenient sample consists of subjects included in the study because they happen to be in the right place at the right time. Respondents who met the sample criteria were identified by the researchers at Iligan City National High School. A non-probability sampling is meant to convince the researchers to participate and share their views. Thus, the respondents were chosen, a maximum standard of 100 respondents, 19 from the Grade 10 Junior High School, 34 from Grade 12 and 33 from Grade 11 senior high school. Since the researchers got to choose the respondents in this present study, there will be 14 respondents from teachers from high school department (Table 1).

\section{Sampling procedure}

In Iligan City National High School has the most number of students in the city. Through non-probability sampling, the researchers choose among the students in the campus that could highly participate in this present study. Also, in choosing the respondents, the researchers could get the information and data that is needed in this present study. A non-probability sampling technique is that samples are selected based on the subjective judgment of the researchers and also the researchers are competent enough that there will be no biases among the choosing respondents.

\section{Data gathering procedure}

In this study it will elude opinions and elicit numerical data from the respondents through survey or questionnaire. It is a closed-ended question. Questionnaires were personally distributed by the researchers to the selected senior high school students from grade 11 to grade 12 and to the teachers. The data was collected over a period of 5 days. The researchers roam from room to room in order to distribute the questionnaire to the chosen respondents. The papers are separated by gender. When a questionnaire is used as a data gathering instrument, it is necessary to determine whether questions and directions are clear to subjects and whether they understand what is required from them.

\section{Instrument used}

Various kinds of rating scales have been developed to measure attitudes directly (i.e. the person knows their attitude is being studied).

\begin{tabular}{|c|c|}
\hline Respondents & Quantity \\
\hline Grade 10 & 19 \\
\hline Grade 11 & 33 \\
\hline Grade 12 & 34 \\
\hline Teachers & 14 \\
\hline Total respondents & 100 \\
\hline
\end{tabular}

Table 1: Respondents from teachers from high school department.

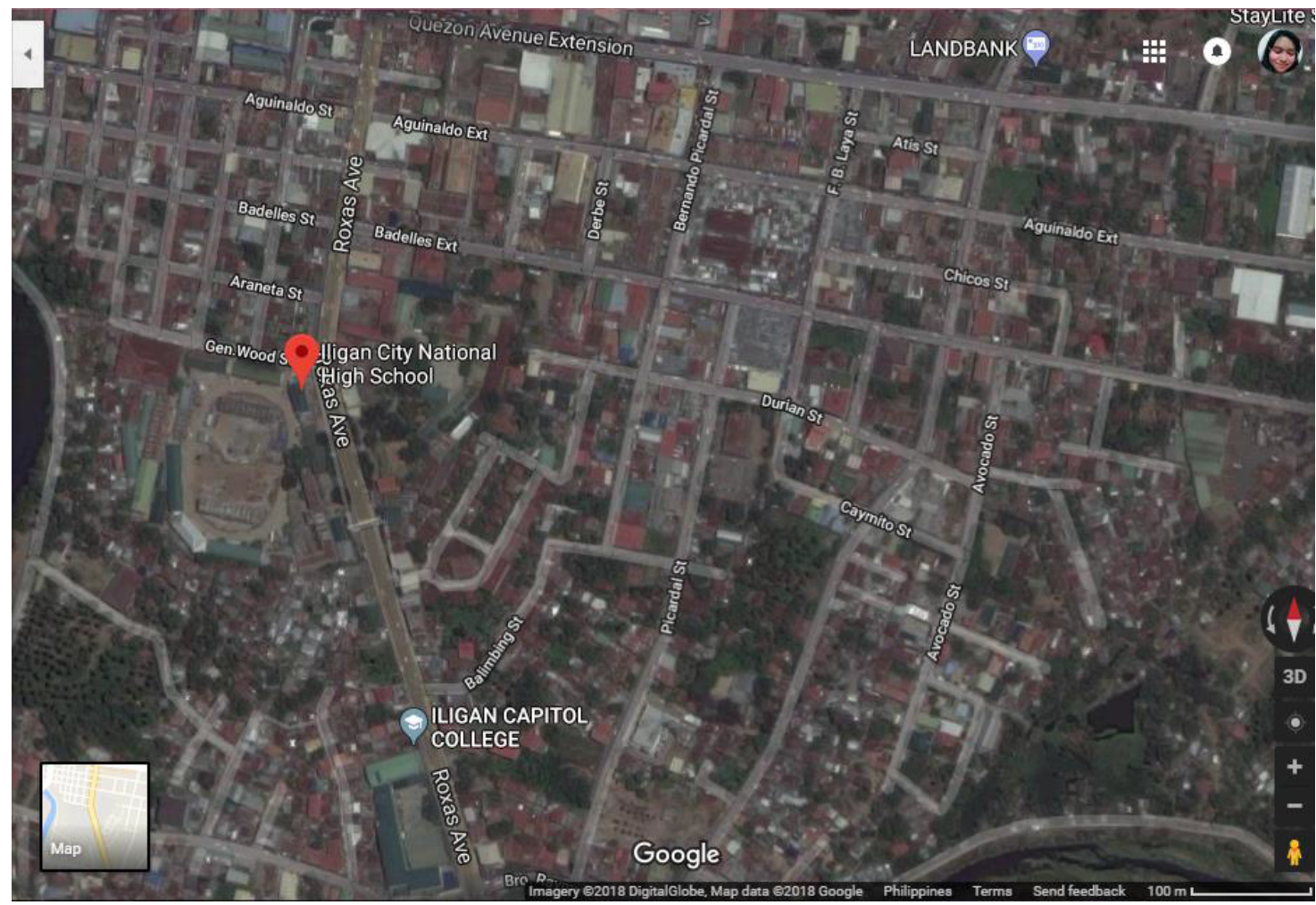

Figure 2: Satellite image of Iligan Capitol college. 
The most widely used is the Likert Scale. Likert Scale is a psychometric scale commonly involved in research that employs questionnaires. It is the most widely used approach to scaling responses in survey research, such that the term (or more accurately the Likert type scale) is often used interchangeably with rating scale, although there are other types of rating scales. It also assumes that the strength/intensity of experience is linear, i.e. on a continuum from strongly agree to strongly disagree, and makes the assumptions that attitudes can be measured. Respondents may be offered a choice of five to seven or even nine pre-coded responses with the neutral point being neither agree nor disagree. In its final form, the Likert scale is a five (or seven) point scale which is used to allow the individual to express how much they agree or disagree with a particular statement. Likert developed the principle of measuring attitudes by asking people to respond to a series of statements about a topic, in terms of the extent to which they agree with them, and so tapping into the cognitive and affective components of attitudes [6].

\section{Statistical tools}

The present study use descriptive statistics in collecting data and also in analyzing the variables within this study. In getting the attitudes of 100 respondents, it's easy to interpret through using descriptive statistics.

\section{Presentation, Analysis, and Interpretation of Data}

\section{Introduction}

This chapter discusses the data analysis and findings from 100 questionnaires completed by the chosen respondents from Iligan City National High School who took part in this present study. The purpose of this study was to give analysis of the following data: respondents' profile such as students from different levels and teachers from senior high school department, and attitudes that molded their views towards LGBT. Data were obtained from self-administered questionnaires completed by 100 respondents $(n=100) .34$ from grade $12(n=34)$, a $34 \%$ in response rate, 33 from grade $11(\mathrm{n}=33)$, a $33 \%$ in response rate, 19 from grade $10(\mathrm{n}=19)$, a $19 \%$ in response rate, and 14 from teachers in senior high school department $(\mathrm{n}=14)$, a $14 \%$ in response rate for a total of $100 \%$.

\section{Methods of data analysis and presentation of data}

Descriptive analysis was used in identify frequencies and percentage to answer all of the survey questions. All of the respondents were able to answer the survey questions therefore percentages correspond to the total number of respondents answering the individual survey. The statistical significance of relationships among selected variables was determined using the Likert' type scale [6]. The level of significance was set at 0.20 .

\section{Respondents' profile}

Respondents were chosen based on their grade level and followed by the teachers which are also participated in this present study (Table 2).

\begin{tabular}{|c|c|c|}
\hline Response & Frequency & Percentage \\
\hline Grade 12 & 34 & 0.34 \\
\hline Grade 11 & 33 & 0.33 \\
\hline Grade 10 & 19 & 0.19 \\
\hline Teachers & 14 & 0.14 \\
\hline & & Total: $100 \%$ \\
\hline
\end{tabular}

Table 2: Data of the following respondents.

\section{Data analysis-procedure}

The procedure followed for analysing the data will be discussed first, after which the presentation of the data follows. The researchers engaged with the data inductively, approaching the data from the particular to general perspectives (Figure 3).

The pie chart above shows that $2.12 \%$ of the respondents are neutral which means that some of the respondents are unsure if LGBT people are strange, sick, crazy and perverse. Followed by $2.02 \%$ that shows the respondents are strongly disagreed (Figure 4).

It is clear that $3.32 \%$ of the respondents agree that LGBT people are born that way and, therefore, should be pitied (Figure 5).

As shown above, $2.63 \%$ of the respondents are strongly agree that same-sex attractions and gender non-conforming behaviours are just a phase of development that most people outgrow (Figure 6).

The pie chart implied that $2.51 \%$ of the respondents are agree that

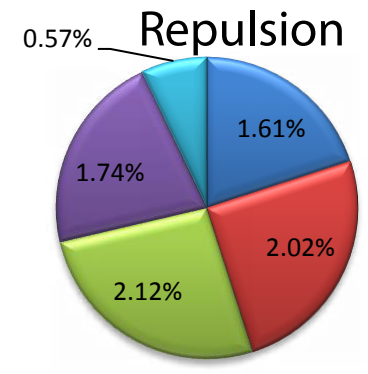

$\square$ Strongly Disagree

$\square$ Disagree

$\square$ Neutra

$\square$ Agree

$\square$ Strongly Agree

Note $n=100$; Primary data.

Figure 3: Data of the attitudes in terms of repulsion

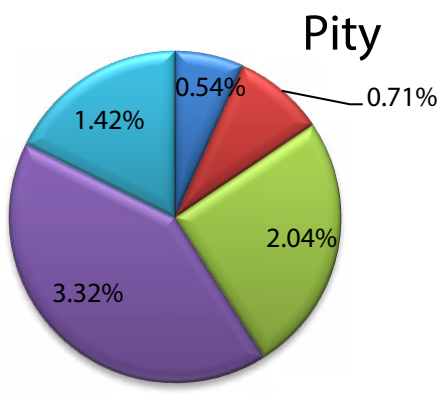

Q Strongly Disagree

Disagree

$\square$ Neutral

$\square$ Agree

$\square$ Strongly Agree

Note $n=100$; Primary data.

Figure 4: Data of the attitudes in terms of pity.

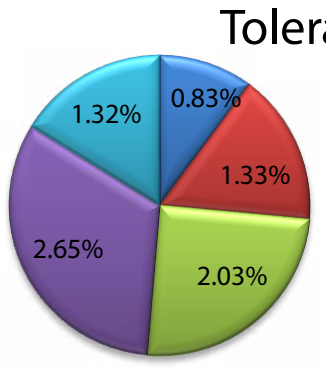

- Strongly Disagree

๑Disagree

$\square$ Neutral

$\square$ Agree

$\square$ Strongly Agree

Figure 5: Data of attitude in terms of tolerance. 
one needs to make accommodations for LGBT people's difference; although they are not as valued as heterosexual, gender-conforming people (Figure 7).

The pie diagrams indicate that $1.99 \%$ of the respondents are neutral if the rights of LGBT people should be protected and safeguarded (Figure 8).

$3.28 \%$ out of 100 respondents agree that being an LGBT person in our society takes strength (Figure 9).

The pie diagram indicates that $2.63 \%$ out of the 100 respondents are neutral. That means that some of the respondents are still unsure if the LGBT people are an indispensable part of our society [7-9].

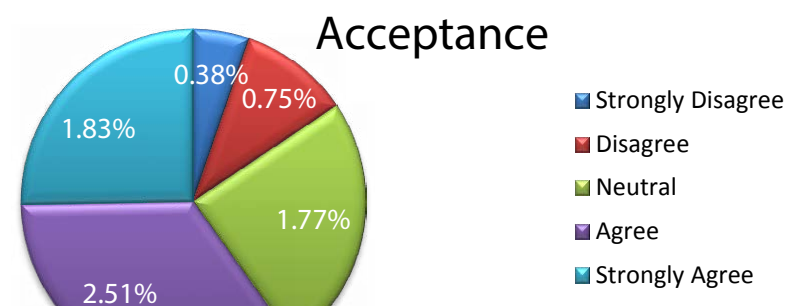

Note $n=100$; Primary data.

Figure 6: Data of attitude in terms of acceptance.

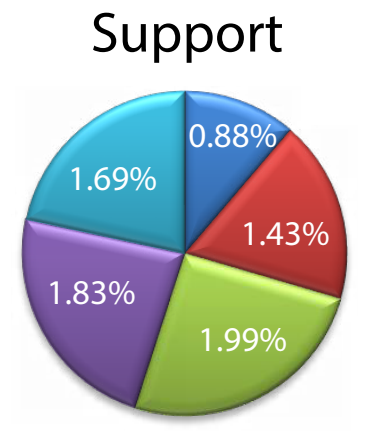

$\square$ Strongly Disagree

$\square$ Disagree

$\square$ Neutral

$\square$ Agree

$\square$ Strongly Agree

Note $n=100$; Primary data.

Figure 7: Data of attitude in the terms of support.

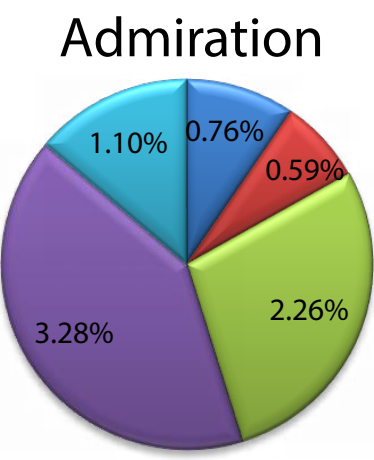

$\square$ Strongly Disagree
Disagree
$\square$ Neutral
Disagree
Strongly Agree

Note $n=100$; Primary data.

Figure 8: Data of attitude in the terms of admiration.

\section{Data interpretation and discussion}

The study was engaged with quantitative data analysis procedure where descriptive statistics such as frequencies, percentages, and means were used. The statistical package for social sciences (SPSS, version 17) was used in order to run the descriptive statistics. Tables and figures were used to summarize data [10-12]. The following data was derived from the chosen respondents which are teachers and students' questionnaires. The data were gathered about the attitudes of the respondents that shape their perceptions towards LGBT people.

The Table 2 discussed the respondents percentage on how many respondents does each group have. After the data was collected, a pie diagram was made. In accordance to the data, an attitude was discovered based on the answers of the following respondents.

It is understood that majority of the respondents have already accepted the LGBT people in the campus, to be specific, in Iligan City National High School (Table 3).

The Table 2 above shows the percentage of the respondents in terms of different attitudes that indicated in each statement. $45.11 \%$ out of the 100 respondents have already made up their perceptions towards LGBT people based on the given attitudes in each number. While $54.89 \%$ of the respondents are still on the state of confusion whether they should interact more with LGBT people or make themselves distant from the LGBT community. In questions number 1-4, 7.05\% of the respondents have personal feelings that may be preventing them from being accepting and supportive of LGBT people while $4.88 \%$ of the respondents don't have personal feelings and that makes them accept and support the LGBT people [13]. In number 5-8, 8.31\% of the respondents are somewhat accepting and supporting LGBT people but still have areas in which to grow in order to be an effective ally. In number $9-12,7.9 \%$ of the respondents are ready to be an effective ally

\begin{tabular}{|c|c|c|c|c|}
\hline Questions\# & Total\% & $\begin{array}{c}\text { Strongly } \\
\text { Disagree+Disagree }\end{array}$ & $\begin{array}{c}\text { Strongly } \\
\text { agree+Agree }\end{array}$ & $\begin{array}{c}\text { \# of } \\
\text { attitudes }\end{array}$ \\
\hline $1-4$ & $11.39 \%$ & $4.88 \%$ & $7.05 \%$ & 2 \\
\hline $5-8$ & $11.6 \%$ & $3.29 \%$ & $8.31 \%$ & 2 \\
\hline $9-12$ & $11.56 \%$ & $3.66 \%$ & $7.9 \%$ & 2 \\
\hline $13-16$ & $10.67 \%$ & $2.9 \%$ & $7.77 \%$ & 2 \\
\hline $\begin{array}{c}\text { Total percentage of } \\
\text { the respondents: }\end{array}$ & $=45.11 \%$ & $=14.73 \%$ & $=31.03 \%$ & \\
\hline
\end{tabular}

Table 3: Data interpretation of respondents answering SD, D, SA and A.

\section{Appreciation}

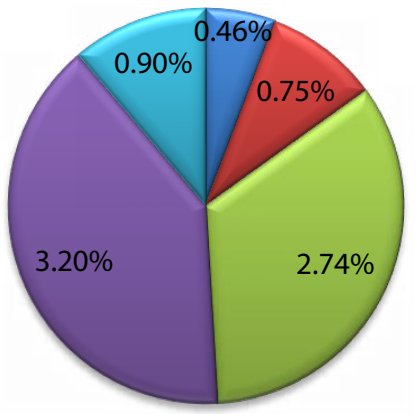

$\square$ Strongly Disagree

口Disagree

$\square$ Neutral

$\square$ Agree

口Strongly Agree

Note $\mathrm{n}=100$; Primary data

Figure 9: Data of attitudes in the terms of appreciation. 
to LGBT people. In number $13-16,7.77 \%$ of the respondents are able to be an effective ally to LGBT people (Figure 10).

\section{Nurturance}

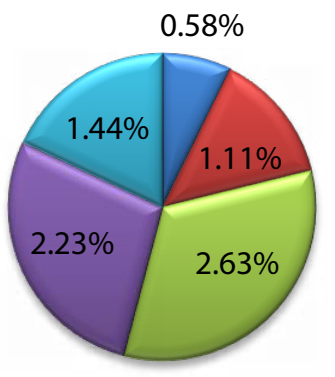

$\square$ Strongly Disagree
Disagree
$\square$ Neutral
$\square$ Agree

$\square$ Strongly Agree

Figure 10: Data of attitudes in the terms of Nurturance.

\section{Summary of Findings, Conclusion, and Recommendations}

\section{Overview}

The purpose of this chapter is to present the summary, conclusions, and the recommendations made as an outgrowth of this present study (Table 3).

The main problem in the study is how people approach and interact with the LGBT people. With the help of the respondents, the researchers was able to determine their attitudes towards LGBT and by that the researchers have discovered on how they treat, interact, and approach the LGBT based on the given attitudes. The following attitudes will reflect on how people dealt with LGBT people: pity, repulsion, tolerance, acceptance, support, admiration, appreciation, and nurturance $[14,15]$.

The purpose of this study is to change people's perspective about the LGBT in the society. To make them aware of their treatment that somehow might change either positive or negative. To know their views that can be share to the readers. To benefits the society in terms of gender equality.

This present study was digging the attitudes of people towards the LGBT. The research design focused on the following questions:

1. How do people interact and approach the LGBT people?

2. Why do they view the LGBT in that way?

3. What makes their attitudes shape their perception?

100 respondents are being surveyed. Self-administered questionnaire have done. The present study is to know the attitudes of people in the society and how they engage with the homosexuality people. This study is only limited in giving the attitudes of LGBT people. Only 100 respondents are surveyed which are divided into three groups: the junior high school, senior high school, and the teachers. The study used the non-probability sampling to easily capture the knowledge and views. Homosexuality and heterosexuality are parts of the respondents. There are no biases in this study. There are no interviews or observations happened.

This section presents the summary of the findings of the 2 research questions:

- The literature discovered an attitude towards LGBT people.
The first question sought to understand the attitudes of the respondents. The question asked: How do people view LGBT?

- Some of the respondents view LGBT people as strange and they should be pitied. Based on the data gathered, there are only few people who are still have personal feelings that may prevent them from accepting the LGBT. Thus, they have the following attitudes: repulsion, pity, tolerance, and acceptance.

- Second question sought to get the basis of the respondents on shaping their attitudes towards LGBT. The question asked: What makes people attitudes shapes their own perceptions?

Since the researchers only conducted survey to the following respondents, then their attitudes will based on their answer of the statements in the questionnaire. In questionnaire number 9-10, 3.28\% of the respondents answered agree. Therefore they agree that the rights of LGBT should be protected that shows they're supporting LGBT.

\section{Summary of the findings}

The salient findings of the study are as follows:

1. People approach, interact, and view LGBT people as part of the community but on the percentage of $14 \%$, there are still people who tolerate LGBT and tend to have a negative reactions towards them. On the other hand, $43 \%$ of the respondents have already accepted LGBT and are able to become one of the ally of the LGBT. $43 \%$ of the respondents viewed the same way, positive and negative.

2. The study distinguished the attitudes of people towards LGBT people in terms of:

- $1.61 \%$ disagreed that LGBT people are strange, sick, crazy and perverse while $1.74 \%$ agree that statement. Thus, they're attitudes is repulsion.

- $3.32 \%$ of the respondents agree that LGBT people are born that way, therefore, they should be pitied.

- $1.33 \%$ of the respondents disagree on the statement that samesex attractions and gender non-conforming behaviours are just a phase of development that most people outgrow. In that way, they are tolerating LGBT people.

- $2.65 \%$ agree on statements number $7-8$, therefore, one needs to make accommodations for LGBT people's difference; although they are not as valued as heterosexual, gender conforming people.

- $2.51 \%$ of the respondents support the LGBT people.

- $3.28 \%$ of the respondents admired the LGBT because of their strength.

- $3.20 \%$ out of 100 respondents agree that being an LGBT has value in diversity. Thus, homophobic attitudes should be confronted

- $2.63 \%$ of the respondents agree that LGBT people are indispensable part of the society.

- One's rating is based on the clusters of statements that most accurately reflect one's current beliefs. Hence, their perceptions and views shape their attitudes towards LGBT people.

\section{Conclusion}

As a result of this study, it is the researchers hope that attitude 
towards LGBT people are clearly understood by the readers. Overall, this study had already attained what it wants. The data shows that support and admiration is the top attitude that the respondents showed towards the LGBT people. The perceptions of people differ from how they see the LGBT community. Therefore, there are still negative attitudes remained such as pity, tolerance, and repulsion but majority are of them are positive attitudes. Thus, their views shape their attitudes towards LGBT people.

\section{Recommendations}

The conclusion of the research addressed the attitudes of people towards LGBT that it differs on how they see. The answer of a respondents have a big impact in comes of rating. Based on the findings and conclusion presented, the following recommendations are suggested.

1. The researchers recommend no matter what is the gender of an individual it should be respected and views equally.

2. The researchers recommend that gender equality should be addressed in the society.

3. The researchers recommend that People should continue supporting LGBT.

4. The researchers recommend that rights and protection should be implemented among the individuals of LGBT for the fact that there is still discrimination among the third sex community.

5. People should be open-minded about LGBT.

\section{Acknowledgement}

The researcher wishes to express appreciation and profound gratitude to the following persons who gave their support, cooperation and consideration for the success of this study.

First and foremost, praises and thanks to God, the Almighty, for His showers of blessings throughout our research work to complete the research successfully;

Our parents, for their love, prayers, caring and sacrifices for educating preparing us for our future;

Prof. Joan A. Enad, the researcher adviser, for her deep concern, sincere support, witty suggestions and enthusiasm;

To the School Administrators and Staffs of lligan City National High School, for their kindness and support to do this work and to complete this thesis successfully.

Sir Vicente B. Lluisma Jr., the department head of academic and sports track, thank you for giving us undying support for this thesis;
Sir Jose E. Salvador, the school assistant principal, for also giving the permission to conduct this study

Sir Rex Lao Razo, the researcher's school principal, for allowing us to conduct the study.

\section{References}

1. Ahmad M (2008) Comprehensive Dictionary of Education New Delhi: Atlantic Publishers \& Distributors (p) Ltd.

2. Steffens MC, Wagner $C$ (2004) Attitudes toward lesbians gay men bisexual women and bisexual men in Germany. J Sex Res 41: 137-149.

3. Harper GW (2007) Sex isn't that simple: culture and context in HIV prevention interventions for gay and bisexual male adolescents. Am Psychol 62: 806-819.

4. Paul F, Bader C, Smith B (2008) Political Tolerance and God's Wrath in the United States Sociology of Religion 69: 29-44.

5. Bader CD, Froese P (2005) Images of God: The Effects of Personal Theologies on Moral Attitudes Political Affiliation and Religious Behavior Interdisciplinary. Journal of Religious Research 10: 160-173.

6. Likert R (1932) A Technique for the Measurement of Attitudes Archives of Psychology 140: 1-55.

7. Moore DS, McCabe GP (2006) Introduction to the Practice of Statistics. Fifth Edition Freeman, p: 219

8. Herek GM, Glunt EK (1993) Interpersonal contact and heterosexuals' attitudes toward gay men: Results from a national survey. Journal of Sex Research 30 239-244.

9. D'Auge lli AR (1992) Teaching lesbian/gay development: From oppression to exceptionality. Journal of Homosexuality 22: 213-227.

10. Raja S, Stokes JP (1998) Assessing attitudes toward lesbians and gay men: The modern homophobia scale. Journal of Gay Lesbian and Bisexual Identity 3: 113-134.

11. Herek GM (2002) Gender gaps in public opinion and lesbians and gay men Public Opinion Quarterly 66: 40-66.

12. Newport $F$ (2001) American attitudes towards homosexuality continue to become more tolerant.

13. Blashill AJ, Powlishta KK (2008) Gaystereotypes: The use of sexual orientation as acue for gender-related attributes Manuscriptsubmitted for publication. The Impact of Sexual Orientation and Gender Role on Evaluations of Men

14. Bader CD, Mencken FC, Froese P (2005) American Piety: Content Methods and Selected Results from the Baylor Religion Survey. Journal for the Scientific Study of Religion 46: 447-463.

15. Aguero JE, Bloch L, Byrne D (1984) The relationships among sexual beliefs attitudes experience and homophobia. Journal of Homosexuality 10: 95-107. 